\title{
Effectiveness of De-Stressful Skills Training On Reducing the Distress of Women Infected by Breast Cancer
}

\author{
Fatemeh Givi ${ }^{1 *}$, Farah Lotfi Kashani ${ }^{2}$, Shahram Vaziri ${ }^{3}$, \\ Mohamad Esmaeil Akbari ${ }^{4}$
}

\section{ABSTRACT}

Any changes in human's life is along with stress, as well as diagnosis of cancer occurs the unique distress for the patient. The objective of the extant paper is determining the effectiveness of training the skills of confronting the stress for reducing the distress of women infected by breast cancer. Therefore, 23 women infected by breast cancer referring to Shohada Hospital of Shahid Beheshti University of Medical Sciences in Tehran by means of convenience and random sampling in two test (12 samples) and control (11 samples) groups. All examinees were evaluated firstly as respect to the distress rate by means of Kessler's distress assessment scale (K10), then de-stressing manner was trained to the test group during 8 sessions each one 90 minute. Control group has received any intermediation. The results of analysis of covariance of distress scores indicated that training stressful skills is effective on reducing the distress of women infected by breast cancer.

Keywords: De-Stressful Skills Training, Women, Breast Cancer

Breast cancer is one of the prevalent diseases in Iran and the world. Some statistics imply that out of 8 women, one person has the chance of infecting by this disease. As per the report of Akbari (2006), every year 1063 persons lose their life due to catching to this disease. Although the existing advances for treating this disease has upraised the lifetime from $75 \%$ in 1970 s to $87 \%$ in 1990, but yet these patients are involved in complications such as pain and distress.

Diagnosing and exposing to treatments related to breast cancer may incur a lot of stress directly and indirectly on the infected person. This stress according to the description of Sile (1946)

\footnotetext{
${ }^{1}$ M.A In clinical psychology, Department Of Psychology, Islamic Azad University of Rudehen Branch, Tehran, Iran

${ }^{2}$ Department Of Psychology, Islamic Azad University of Rudehen Branch, Tehran, Iran

${ }^{3}$ Department Of Psychology, Islamic Azad University of Rudehen Branch, Tehran, Iran

${ }^{4}$ Cancer Research Center, Shahid Beheshti University of Medical Sciences, Tehran, Iran

*Responding Author

(C) 2016 I F Givi, F Kashani, S Vaziri, M Akbari; licensee IJIP. This is an Open Access Research distributed under the terms of the Creative Commons Attribution License (http://creativecommons.org/licenses/by/2.0), which permits unrestricted use, distribution, and reproduction in any Medium, provided the original work is properly cited.
} 


\section{Effectiveness of De-Stressful Skills Training On Reducing the Distress of Women Infected by Breast Cancer}

creates a warning reaction at the first stage that is an automatic response and the person has no considerable conscious control thereon. In continue, this body process attempts by resistance to return to its balance and relaxation and if this resistance doesn't return the balance and relaxation they will be involved in exhaustion and distress. This distress causes the weakness of immune system in a deficient revolving reaction and provides the changeability of early disease to the advancer status. The distress that includes the extensive concept of proprietary symptoms such as concern on disease and reduction of health, depression, anxiety, anger, sleep disorders, reduction of appetite, focusing disorders and sense distress along with fear from inability and death has a lot effect on disease and patient's life.

While revising distress occurrence it is observed that diagnosing cancer due to the implied meanings of this diagnosis in the patient \& family's mind such as probability of deformity, pain, financial and social problems, disruption of family structure, death and some real events results in some deep emotional and exciting problems for the patient and his family. Fearing from relapse, beginning of treatment, accepting painful medicinal treatments, waiting for test results, combating against uncontrollable pains, pain, reduction of social activities and inability, radiotherapy and chemotherapy make these patients more distressful and limit the perception of their ability for coordinating the life conditions with the existing stress as a situation out of tolerance, such conditions reduce the patient's health feeling and effectiveness of individuals effective on their improvement. Upon increasing the depression and anxiety, lack of enjoy feeling, taking distance from friends or family, lack of motivation and failure bearing, reduction of sexual desire, increasing or decreasing appetite and weight, reduction of energy and premature fatige, sleep disorder become incident, in other word, the resistance force is weakened against tumor and again the distress including anxiety, depression and fear become more acute. Due to this revolving reaction, the researches show that within 50 to $85 \%$ of patients infected by cancer suffer from a psychiatric disorder concurrently.

The distress requires the immediate management in order to avoid the patient's problems not to become more complicated. As Bridin, Canner, Chrichnazami \& Plant (1999) have reported, any action for reducing the distress rate will have very important effect on the improvement of enormous amount of symptoms and signs resulted from cancer and controlling actions. Sometimes, the patient's distress leads the patient towards choosing uncommon treatment methods and as a result postponing the main treatments. Thus, treating the distress is a part of patient's main treatment that should be commenced since the same first stage and to be continued until the end of treatment.

The researches indicate that psychological interventions may reduce the emotional distress of these patients including anxiety, fear, concern and anger and improve the quality of their life and self-esteem and increase their immune system and satisfaction with life. Whist, the studies show

(C) The International Journal of Indian Psychology, ISSN 2348-5396 (e) | ISSN: 2349-3429 (p) | 186 


\section{Effectiveness of De-Stressful Skills Training On Reducing the Distress of Women Infected by Breast Cancer}

that self-supposing thought, cognitive mistakes, training level, and aiming based on concern and anxiety have considerable role in occurrence of psychological problems of these patients and coping and confronting based on negative excitement increase the distress of whom infected by breast cancer, it seems if the cognitive ability of patients infected by cancer is increased and learn them some methods to how avoid from meditating about stressful subjects and how reduce their emotional turmoil level, their psychological distress of these patients may be reduced successfully.

Altogether, it seems the cancerous patients need to express their feelings, receive their required protection and learn the required coping skills. In this study, it is attempted to reduce the distress resulted from breast cancer of patients by training the de-stressful skills such as relaxation by deep breaths, learning the focus on present, changing the intellectual forms and replacing the positive inner whispers instead of negative inner whispers, avoiding from disaster-making, sympathy and attracting social protections, laughing and walking.

\section{Procedure:}

The extant quasi-experimental study has been applied as a pretest-posttest design by the control group. The studied statistical population of this study is consisted of women infected by breast cancer referring to Shohada Hospital of Shahid Beheshti University of Medical Sciences within the age range of 20-65 and educational lever higher than middle school diploma. Out of this population, 23 persons were selected via random convenience sampling and were divided in two test (12 persons) and control (11 persons) groups randomly. The conditions for admitting treatment included passing at least 3 months after chemotherapy, having at least middle school diploma, lack of relapse and lack of using psychiatric drugs and conditions for exiting from study is not passing 3 months after chemotherapy, literacy less than middle school diploma, relapse and using psychiatric drugs. For observing the moral codes of all examinees of treatment process, the treatment period of the informed and written satisfaction of individuals for admitting in the research were obtained.

The control group was told to wait for the beginning the course as the waiting group for one month. After completion of course, training method was applied for them.

The de-stressing skills including deep breathing, consciousness, thinking styles, sympathy, problem solving, establishing communication, social protection, laugh and walking were trained to the test group twice per week, each session 90min, and for one month. The both groups before beginning the intermediations and after 8 sessions were assessed aiding Kessler's distress assessment scale (K10). 


\section{Effectiveness of De-Stressful Skills Training On Reducing the Distress of Women Infected by Breast Cancer}

For collecting data, Kessler psychological distress assessment scale 10 (K10) was used. This scale that has been designed for identification of distress rate of the publics during the recent month has been introduced by Kessler (2003). This scale has been compiled by Kessler et al in 2002 as a 10 item scale. The questions answer had 5 options (ever, most times, sometimes, rarely and never) and each answer is scored between 0 to 4 . Forokava (2003) has confirmed the validity of K10 for diagnosing the mood and anxiety disorders. Fessart (2009) has reported the reliability of this test by Cronbach's alpha coefficient equal to 0.93. Donker (2010) has reported the reliability of this test equal to 0.93 and declared that the high scores in this scale have close relationship with diagnostic scores of major depression, anxiety, social phobia, phobia disorder, and agoraphobia. This scale of Vaziri \& Lotfi Kashani (2011) in a survey study have reported the reliability of Kessler scale K10 by Cronbach's alpha coefficient equal to 0.93 and correlation between the scores of this scale by means of GHQ28 equal to 0.83 .

In this study, test group were trained by de-stressing skills. This treatment program has been drafted by Vaziri \& Lotfi Kashani based on the available backgrounds and management methods and confronting stress considering the needs of patients infected by breast cancer. This package has been executed as 8 sessions each $90 \mathrm{~min}$. in table 1, the applied intermediation plan has been reported for each session separately.

Table 1: De-stressing plan for the patients infected by breast cancer for each session separately:

\begin{tabular}{|l|l|}
\hline First session & $\begin{array}{l}\text { Familiarizing the group member to each other and psychotherapist, } \\
\text { familiarizing the group members to the regulations of group therapy, } \\
\text { introduction to stress, training the relaxation by deep breathing, presenting } \\
\text { practice, requesting for relaxation by breathing in middle of therapy sessions as } \\
\text { the practice }\end{array}$ \\
\hline $\begin{array}{l}\text { Second } \\
\text { session }\end{array}$ & $\begin{array}{l}\text { Examining the practice results of first session, explaining the importance of } \\
\text { being at present and life in present time and its effects in psychological status, } \\
\text { practicing consciousness as the method for being in present, requesting for } \\
\text { relaxation practice by breathing and consciousness in middle of therapy } \\
\text { sessions as the practice }\end{array}$ \\
\hline Third session & $\begin{array}{l}\text { Examining the results of second session practice, explaining the importance of } \\
\text { laughing and joy, practicing laugh, requesting for relaxation by breathing and } \\
\text { consciousness and laugh in middle of therapy sessions as the practice }\end{array}$ \\
\hline Fourth & $\begin{array}{l}\text { Examining the results of third session practices, explaining the importance of } \\
\text { thought and beliefs based on the disaster-making, practicing the change in } \\
\text { intellectual form and replacing positive inner whispers instead of negative inner } \\
\text { whispers, requesting for practicing relaxation by breathing, replacing the } \\
\text { positive inner whispers instead of negative inner whispers, consciousness and } \\
\text { laugh in middle of therapy sessions as the practice }\end{array}$ \\
\hline
\end{tabular}

(c) The International Journal of Indian Psychology, ISSN 2348-5396 (e)| ISSN: 2349-3429 (p) | 188 


\section{Effectiveness of De-Stressful Skills Training On Reducing the Distress of Women Infected by Breast Cancer}

\begin{tabular}{|l|l|}
\hline Fifth session & $\begin{array}{l}\text { Examining the results of fourth session practices, familiarizing the individuals } \\
\text { to the effects of social protection and its role in psychological status, practicing } \\
\text { the attraction of social protection and foundation of assistance group and } \\
\text { admitting the close members and spouses therein, requesting for practicing } \\
\text { relaxation by breathing, replacing the positive inner whispers instead of } \\
\text { negative inner whispers, consciousness and laugh along with practice of } \\
\text { attracting the social protection in middle of therapy sessions as the practice }\end{array}$ \\
\hline Sixth session & $\begin{array}{l}\text { Examining the results of fifth session practice, explaining the importance of } \\
\text { walking, requesting for relaxation by breathing, replacing the positive inner } \\
\text { whispers instead of negative inner whispers, consciousness and laugh, } \\
\text { attracting the social protection and walking in middle of therapy sessions as the } \\
\text { practice }\end{array}$ \\
\hline Seventh & $\begin{array}{l}\text { Examining the results of relaxation by breathing, replacing the positive inner } \\
\text { whispers instead of negative inner whispers, consciousness and laugh, } \\
\text { attracting the social protection and walking in middle of therapy sessions and } \\
\text { explaining the individual experiences }\end{array}$ \\
\hline Eighth session & $\begin{array}{l}\text { Examining the results of relaxation by breathing, replacing the positive inner } \\
\text { whispers instead of negative inner whispers, consciousness and laugh, } \\
\text { attracting the social protection and walking in middle of therapy sessions and } \\
\text { explaining the individual experiences, completing the therapy and requesting } \\
\text { the group to control and protect each other for dealing with daily practices and } \\
\text { holding regular group sessions. }\end{array}$ \\
\hline
\end{tabular}

Whereas in this research, pretest-posttest method with control group has been applied and considering the confirmation and normality of scores distribution by Kolmogorov-Smirnov test and variance homogeneity by Lone test and confirming the regression gradient homogeneity, analysis of variance was used and the data was analyzed by applying SPSS software version 16.

\section{FINDINGS}

The findings indicate that 10 persons (43.3\%) had educational level under high school diploma, 8 persons (34.5\%) high school diploma, 3 persons (13.05) associate's degree and only 2 persons had bachelor's degree or higher educations. 20 persons $(87.4 \%)$ of the participators in this research were married and 3 persons (12.6\%) were single. In table 2, the descriptive elements, the scores of test and control groups' distress in pretest and posttest are presented (table 2). 


\section{Effectiveness of De-Stressful Skills Training On Reducing the Distress of Women Infected by Breast Cancer}

Table 2: Descriptive elements of scores of test and control groups' examinees in distress scale for pretest and posttest separately

\begin{tabular}{|c|c|c|c|c|c|c|}
\hline & \multirow[t]{2}{*}{ Groups } & \multirow[t]{2}{*}{ Number } & \multirow{2}{*}{$\begin{array}{l}\text { Mean } \\
\text { value }\end{array}$} & \multirow{2}{*}{$\begin{array}{l}\text { Standard } \\
\text { deviation }\end{array}$} & \multicolumn{2}{|c|}{ Confidence level of $95 \%$} \\
\hline & & & & & & \\
\hline \multirow[t]{3}{*}{ Pretest } & Test & 12 & 27.00 & 2.594 & 25.35 & 28.65 \\
\hline & Control & 11 & 24.73 & 6.310 & 20.49 & 28.97 \\
\hline & Total & 23 & 25.91 & 4.776 & 23.85 & 27.98 \\
\hline \multirow[t]{3}{*}{ Posttest } & Test & 12 & 17.75 & 1.138 & 17.03 & 18.47 \\
\hline & Control & 11 & 22.36 & 6.680 & 17.76 & 28.97 \\
\hline & Total & 23 & 19.96 & 5.253 & 17.69 & 22.23 \\
\hline
\end{tabular}

Analysis of covariance has been provided for specifying if the applied procedure has had effective significant effect on distress posttest scores or not. Normality and uniformity of dependent variable variance was confirmed by Lone test $(\mathrm{F}=3.929, \mathrm{df}=1,21, \mathrm{p}=0.061)$. Examining the regression homogeneity indicates that the interaction between conditions and pretest is not significant, consequently, the data protects the homogeneity of regression gradients. Analysis of regression chart's graphic confirms as well as the linear relationship between the auxiliary random variable and dependent variable.

Table 3: Summary of analysis of covariance (ANCOVA) for reviewing the effect of intervention on distress of women infected by breast cancer

\begin{tabular}{|l|l|l|l|l|l|l|l|}
\hline Change resource & SS & df & MS & F & Sig. & PES & OP \\
\hline Pretest & 249.292 & 1 & 249.292 & 21.171 & 0.001 & 0.514 & 0.992 \\
\hline Main effect of groups & 211.956 & 1 & 211.958 & 18 & 0.001 & 0.474 & 0.981 \\
\hline Remained error & 235.503 & 20 & 11.775 & & & & \\
\hline
\end{tabular}

As it is observed in table 3, summary of analysis of variance indicates that by eliminating the effect of pretest scores, the main effect of intervention on scores of distress posttest for women infected by breast cancer is significant $\left(\mathrm{F}=18,1,20, \mathrm{p}<0.001\right.$, partialn $\left.{ }^{2}=0.981\right)$.

\section{DISCUSSION AND CONCLUSION}

Many of diseases are in connection with stress and whatever the stress is more severe and longer will provide more negative psychological and physiological complications. It seems, the life's stressful occurrences in addition to increasing the probability of infection by different diseases are effective on severity or trend of disease. This effect in relation to cancer types has been considered somewhat. Diagnosis of cancer incurs considerable and extraordinary stress on the individual and threatens his life. Upon continuation of stress and finishing the individual's power for resistance against stress, the individual enters into psychological distress status. Psychological distress is somehow the result of individual's inability versus acute psychological pressure that in other front causes the weakness in immune system and loss of its response. This research has been applied for investigating the effectiveness of de-stressing skills training for

(c) The International Journal of Indian Psychology, ISSN 2348-5396 (e)| ISSN: 2349-3429 (p) | 190 


\section{Effectiveness of De-Stressful Skills Training On Reducing the Distress of Women Infected by Breast Cancer}

reduction of distress of women infected by breast cancer. The findings indicated that training the de- stressing skills including relaxation by deep breathing, learning the focus on present, changing the intellectual form and replacing positive inner whispers instead of negative inner whispers, avoiding from disaster-making, sympathy and attracting the social protections, laugh, and walking are effective on reducing the distress of women infected by breast cancer.

In relation to the findings of extant paper, it is observed that within two recent decades, Loy (1991) showed that good social relationships and protection are in connection with high rate of natural killer $\left(\mathrm{NK}^{2}\right)$ cells that attack the cancer calls and high psychological pressure with low number of these cells. The sport has positive effects on immune system and endocrines of whom suffering from chronic diseases. Oze, DilInsy \& Kamishe (2012) demonstrated that the psychological interventions in group causes the positive perception of social protection and this subject increases the social compatibility and their ability for coping with breast cancer. The researches indicated that social protection as the information and feedbacks we receive from our important loved ones and friends have positive effect for coping with psychological stress and positive excitements (joy, happiness, love and interesting) by motivation lead them forward the new experiences and self-improvement. Therefore, there is a positive relationship between the amount of immune globulin A and kidding for coping with stress.

So, it is concluded that solving the stressful conditions may be an adaptive or non-adaptive manner. Non-adaptive manners such as deny and rejecting along with a short and deceptive relief endangers the individual's health whilst adaptive manners whether in problem-oriented or emotion-oriented provide the conditions that the individual takes action actively for confronting his negative excitements. The sport, establishing social bonds, requesting for protecting the others, combating against negative thoughts, possibility of explaining the stressful event and its aspects to the protectors and talking about negative excitements and important issues of life though as persuading the patients to clarifying the harms and life pains as memoir writing, relaxation training, meditation and resting are considered as the actions may be taken according to the conditions of breast cancer patients in order to reduce the distress.

\section{Acknowledgments}

The author appreciates all those who participated in the study and helped to facilitate the research process.

\section{Conflict of Interests}

The author declared no conflict of interests. 


\section{Effectiveness of De-Stressful Skills Training On Reducing the Distress of Women Infected by Breast Cancer}

\section{REFERENCES}

Ahadi, H., Mehryar, A.H., Nafisi, Gh., Nikoofar, AR., Jahaniyan, S. (1390). Compare coping with stress and depression in three groups of patients with cancer. Thought Journal of Behavior, 6 (21), 35-42.

Ahmadi allouniabadi, A., Fatehizadeh, M., And Sadeghi, H. (1378). Social support for physical and mental health. Week of Esfahan University.

Akbari, M.E. Mousavi, S.M.\& Fallah, R. (2011). Cancer and Emotion, The scope of PsychoSocio-Oncology. At the time of Diagnosis. The 2 th. International Congress on BioEthics. TEHRAN.

Akbari, M.I. Abachyzadh, K. Khayyamzadeh, M. Tabatabai, S.M. asnyashari, F. qnbrymotlagh, A. Majdjbary, Z. (1387). Cancer in Iran. Martyr Beheshti University Cancer Center: Press Daralfkr- Qom.

Akhbardh, Mehdi. (1389). Study of the etiology of chronic stress on the increased risk of cancer. Proceedings of the Third International Congress on Palliative and Supportive Care in Cancer, martyr Beheshti University of Medical Sciences, p. 137.

Alavi, N.S., And Mannai, M. (1388). Anxiety in Patients with Breast Cancer and deal with it. Iranian Journal of Breast Disease, 2 (3 and 4), 43-45.

Aqabrary, M., Ahmadi, F., Muhammadi, I., Hajizadeh, I., And Aghaalinejad, H., (1386). Impact exercise program on stress, anxiety and depression in women with breast cancer undergoing chemotherapy. University of Medical Sciences, 9 (4), 26-35.

Aqabrary, M., Ahmadi, F., Muhammadi, I., Hajizadeh, I., And Varvani farahani, A. (1385). Physical, emotional, mental and social quality of life in women with breast cancer undergoing chemotherapy. Journal of Nursing Research, 1 (3), 55-65.

Atkinson, Rita. Al., Atkinson, R. Si., Smith, Edward. A., Bass, Daryl. C., And Hvksma, Susan. Nolen. Thirteenth Edition. (2000). Hylgard psychology. Translation: Mohammad Taghi Baraheni, Birashk, Mehrdad Beik, Reza Zamani, Saeed Shamloo, M City of votes, and others. (1385). Tehran: growth.

Attar parsai, F., Golchini, M., And Aswadi, I. (1380). The relationship between demographic, social, lifestyle and Stressful factors for breast cancer in women. Medical Journal of Tabriz University of Medical Sciences, 35 (50), 15-23.

Azizi, L. (1382). Investigate the relationship between attachment and psychological adjustment in women with breast cancer (Master's thesis), Allameh Tabatabaei University.

Baider, L., Andritsch, E., Uziely, B., Goldzweig, G., Ever-Hadani, P., Hofman, G., \& et al. (2003). Effects of age on coping and psychological distress in women diagnosed with breast cancer: review of literature and analysis of two different geographical settings. Critical Reviews in Oncology/Hematology, 46(1), 5-16.

Cho, E. A., \& Oh, H. E. (2011). Effect of laughter therapy on depression, quality of life, resilience and immune responses in breast cancer survivors. Journal of Korean Academy of Nursing, 41(3), 285-293. 


\section{Effectiveness of De-Stressful Skills Training On Reducing the Distress of Women Infected by Breast Cancer}

Christopher, K. G., Ronald, D. S., \& Paul, R. F. (2005). Mindfulness and Psychotherapy. New York: Guilford Press.

Cousson-Gélie, F., Bruchon-Schweitzer, M., Atzeni, T., \& Houede, N. (2011). Evaluation of a psychosocial intervention on social support, perceived control, coping strategies, emotional distress, and quality of life of breast cancer patients. Psychological Reports, 108(3), 923-942.

Derogatis, L. R. (1993). The prevalence of psychiatric disorders among cancer patients. Journal of the American Medical Association, 249, 751-757.

Donovan-Kicken, E., \& Caughlin, J. P. (2011). Breast cancer patients' topic avoidance and psychological distress: the mediating role of coping. Journal of Health Psychology, 16(4), 596-606.

Feldman, Robert. (1918). Psychological stress and health. Translation: M Fyrvzbkht and Erfani, Vahide. (1378). Tehran: Shydasb.

Fotoukian, Z. (1382). Quality of life first-degree relatives of patients with cancer care in Mrkzsantral Emam Khomeini in Tehran: (thesis), Iran University of Medical Sciences and Health Services, School of Nursing.

Fotoukian, Z., Ghaffari, F., And Keyhanian, Sh. (1387). Life stressors associated with cancer at the Hospital of Imam Sajjad (AS) Ramsar. Faculty of Nursing and Midwifery, Hamadan, 16 (1 (29)), 11-17.

Furukawa TA, Kessler RC, Slade T, Andrews G. (2003). The performance of the K6 and K10 screening scales for psychological distress in the Australian National Survey of Mental Health and Well-Being. Psychol Med. 2003 Feb;33(2):357-62.

Fury, Neil. (1974). Psychology of Cancer (way back to health and how to cope with emotions due to cancer). Translation: Farid jewelry words. (1373). Tehran: the fall.

Gholamnejad, S. (1389). Compare coping styles in stimulant drug addicts and addicts Afradghyr: (thesis), Azad University Branch.

Heinrichs, N., Zimmermann, T., Huber, B., Herschbach, P., Russell, D. W., \& Baucom, D. H. (2012). Cancer distress reduction with a couple-based skills training: A randomized controlled trial. Annals of Behavioral Medicine, 43(2), 239-252.

Hinnen, C., Ranchor, A.V., Sanderman, R., Snijders, T. A., Hagedoorn, M., Coyne, J. C. (2008). Course of distress in breast cancer patients, their partners, and matched control Couples. Annals of Behavioral Medicine, 36(2), 141-148.

Holland, J. C., Breitbart, W. S., Jacobsen, P. B., Lederberg, M. S., Loscalzo, M. J., \& Mccorkle, M. (2010). Psycho-Oncology. $2^{\text {nd }}$ Edition. New York: Oxford university press.

Kaplan, H., And Sadvk, B. (Without date). Summary of Clinical Psychiatry Behavioral Sciences Psychiatry, Volume II. Translation: N. Pour Afkari. (1381). Tehran: Shahrabi.

Kessler, R. C., Barker, P. R., Colpe, L. J., Epstein, J. F., Gfroerer, J. C., Hiripi, E., \& et al. (2003). Screening for serious mental illness in the general population. Archives of General Psychiatry, 60(2), 184-189.

(C) The International Journal of Indian Psychology, ISSN 2348-5396 (e) | ISSN: 2349-3429 (p) | 193 


\section{Effectiveness of De-Stressful Skills Training On Reducing the Distress of Women Infected by Breast Cancer}

Kessler, R. C., Barker, P. R., Colpe, L. J., Hiripi, E., Mroczec, D. K., Normand, S. L., \& et al. (2002). Short screening scales to monitor population prevalences and trends in nonspecific psychological distress. Psychological Medicine, 32 (6): 959- 976.

Khodayarifard, M., And Parand, A. (1390). Stress and coping with it. second edition. Tehran: Tehran University Press.

Lazaurus, R. S., \& Folkman, S. (1984). Stress Appraisal and Coping. New York: Springer Publishing Company.

Levy, S. M., \& Heiden, I. (1991). Depression, distress and immunity: Risk factors for infectious disease. Stress Medicine, 7(1), 45-51.

Lotfi Kashani, F, Vaziri, Sh. (1389). The role of increasing awareness on mental health in breast cancer patients undergoing chemotherapy. Third International Congress on Palliative and Supportive Care in Cancer. Page 60.

Lotfi Kashani, F, Vaziri, Sh. (1389). The role of relaxation in improving the mental health of cancer patients. Third International Congress on Palliative and Supportive Care in Srtan.s 193.

Mosher, C. E., Duhamel, K. N., Egert, J., Smith, M. Y. (2010). My self-efficacy for coping with cancer in amultiethnic sample of breast cancer patients: associations with barriers toppain management and distress. The Clinical Journal of Pain, 26(3), 227-234.

Mvtaby, F., And Fata., L. (1390). Cognitive-behavioral therapy way in theory. First Edition. Tehran: Publication Danzhh.

Naaman, S., Radwan, K., \& Johnson, S. (2009). Coping with early breast cancer: couple adjustment processes and couple-based intervention. Psychiatry, 72(4), 321-345.

Nedai, M. (1380). Check psychological responses in patients with gastrointestinal cancer risk factors: (thesis), Medical Sciences, Iran, Tehran Psychiatric Institute.

Oz, F., Dil, S., Inci, F., \& Kamisli, S. (2012). Evaluation of group counseling for women with breast cancer in Turkey. Cancer Nursing, 35(4), 27-34.

Pahlavani, H. (1375). Stressors, coping strategies and its relation to mental health in infertile patients (thesis), Tehran Psychiatric Institute.

Pestonjee, D. M. (1992). Stress and coping. New Delhi: Sage Publication.

Peto. J., Collins, N., Barfoot, R., Seal, S., Warren, W., Rahman, N., \& et al. (1999). Prevalence of BRCA1 and BRCA2 gene mutations in patients with early-onset breast cancer .Journal of the National Cancer Institute, 91(11): 943-949.

Pourismail, Z. (1387). The use of alternative medicine in patient care. Proceedings of the First Congress in cancer supportive care and relief, martyr Beheshti University of Medical Sciences, p. 78.

Safai Keshtgar, MR., And Austin, Rob. (1388). Breast Cancer: Basic information for clinical prevention and drawings for patients with breast cancer. First Edition. Tehran: Payame Sefid.

(c) The International Journal of Indian Psychology, ISSN 2348-5396 (e)| ISSN: 2349-3429 (p) | 194 


\section{Effectiveness of De-Stressful Skills Training On Reducing the Distress of Women Infected by Breast Cancer}

Sajadian, A.S., Olfatbakhsh, A., Anbiyai, R., And Haghighat, sh. (1389). Another birth, guide breast cancer. Tehran: Center for Breast Cancer Research, University of Medical Sciences in Tehran.

Sarafynv, E.P. (1940). health Psychology. Translations of translators, under the goddess MIrzaee. (1384). Tehran: growth.

Setayeshi, S., Akbari, ME., Dargahi, R., And Haghighatkhah, HR. (1390). Breast cancer diagnosis and technical analysis. Tehran: Bitarafan.

Van'tspijker, A., Trisburg, R. W., \& Duivenvoorden, H. (1997). A meta-analytic review of 58 studies of cancer. Psychometric Medicine, 59, 280-293.

Vaziri, Sh., Lotfi Kashani, F, Mousavi, M and Akbari, ME. (1388). Amydafzayy role in improving the mental health of cancer patients. Third International Congress on Palliative and Supportive Care in Cancer. Page 121.

Vaziri, Sh., Lotfi Kashani, F, Mousavi, M and Akbari, ME. (1389). The creation of relaxation, increasing awareness, and hope synergies in improving the mental health of cancer patients. Third International Congress on Palliative and Supportive Care in Cancer, p. 122.

Vaziri, Sh., Lotfi Kashani, F. (1390). Validity and reliability of the test Kessler distress. Unpublished academic research.

Vosoughnia, M. (1388). CBT and REBT individual Mdakhlh $\neg$ Hay evaluate the effectiveness of group therapy on depression, anxiety and immune function in cancer patients: (thesis), Azad University Branch.

Zabora, J., Curbow, B., Hooker, C., \& Piantadosi, S. (2001). The prevalence of psychological distress by cancer site. Psycho_Oncology, 32, 19-28.

How to cite this article: F Givi, F Kashani, S Vaziri, M Akbari (2016), Effectiveness of DeStressful Skills Training On Reducing the Distress of Women Infected by Breast Cancer, International Journal of Indian Psychology, Volume 3, Issue 4, No. 57, ISSN 2348-5396 (e), ISSN: 2349-3429 (p), DIP: 18.01.039/20160304, ISBN: 978-1-365-23993-9

(C) The International Journal of Indian Psychology, ISSN 2348-5396 (e) | ISSN: 2349-3429 (p) | 195 